\title{
Perinatal cardiovascular evaluation in Dorper sheep: echocardiographic description and behavior of the heart rate variability on the field
}

Cruz-Aleixo, A.S. ${ }^{1}$; Lima, M.C.F. ${ }^{2}$; Albuquerque, A.L.H. ${ }^{3}$; Teixeira, R.T. ${ }^{4}$; Paula, R.A. ${ }^{5}$; Grandi, M.C. ${ }^{6}$; Ferreira, D.O.L. ${ }^{7}$; Albertino, L.G. ${ }^{8}$; Tsunemi, M.H. ${ }^{9}$; Chiacchio, S.B. ${ }^{10}$; Lourenço, M.L.G. ${ }^{11}$

${ }^{1}$ São Paulo State University (Unesp), School of Veterinary Medicine and Animal Science, Botucatu, São Paulo, Brazil; email: amanda.cruz21@ hotmail.com *Corresponding author. Postal code: Rua Prof. Doutor Walter Mauricio Correa, s/n Bairro: Unesp Campus de Botucatu, CEP: 18618-681 - Botucatu, SP; Phone: (14) 3811-6000; Fax: (14) 3815-2343

${ }^{2}$ São Paulo State University (Unesp), School of Veterinary Medicine and Animal Science, Botucatu, São Paulo, Brazil; email: mayracfl@hotmail.com

${ }^{3}$ São Paulo State University (Unesp), School of Veterinary Medicine and Animal Science, Botucatu, São Paulo, Brazil; email: luisahdealbuquerque@gmail.com

${ }^{4}$ São Paulo State University (Unesp), School of Veterinary Medicine and Animal Science, Botucatu, São Paulo, Brazil; email: rapha_teixeira@hotmail.com

${ }^{5}$ São Paulo State University (Unesp), School of Veterinary Medicine and Animal Science, Botucatu, São Paulo, Brazil; email:medvetrenata@hotmail.com

${ }^{6}$ Diplomate in Veterinary Medicine, Lençóis Paulista, São Paulo, Brazil; email: grandi_vet@yahoo.com.br

${ }^{7}$ Secretary Agriculture of the State of São Paulo, Coordination of Integral Technical Assistance, Office of Development of Bauru, Brazil; email: ferreiradol@gmail.com

${ }^{8}$ São Paulo State University (Unesp), School of Veterinary Medicine and Animal Science, Botucatu, São Paulo, Brazil; email: lukasgalbertino@hotmail.com

${ }^{9}$ São Paulo State University (Unesp), Institute of Biosciences, Botucatu, São Paulo, Brazil; email: $\underline{\text { m.tsunemi@ unesp.br }}$

${ }^{10}$ São Paulo State University (Unesp), School of Veterinary Medicine and Animal Science, Botucatu, São Paulo, Brazil; email: $\underline{\text { sb.chiacchio@unesp.br }}$

${ }^{11}$ São Paulo State University (Unesp), School of Veterinary Medicine and Animal Science, Botucatu, São Paulo, Brazil; email: maria-lucia.lourenco@unesp.br 
Simple summary: The heart is doubly innervated by the autonomic nervous system, with a predominance of sympathetic and parasympathetic activity associated, respectively, with increases and decreases in the heart rate (HR), as illustrated by the Heart Rate Variability (HRV). Pregnancy induces significant changes in the maternal cardiovascular and hemodynamic systems. This study aimed to evaluate the clinical and echocardiographic parameters in Dorper sheep during the gestational period and after delivery. Pregnancy promotes a series of adaptive physiological changes in the mother's body to accommodate the fetus. During pregnancy there were increases in the thickness of the interventricular septum during diastole and in the internal diameter of the left ventricle during systole and diastole at the second and third months, while the ejection fraction increased as the pregnancy progressed. The size of the left atrium increased starting at the second month. In sheep, the gestation period leads to alterations in the clinical parameters and in the activity of the autonomic nervous system. As the pregnancy advances, there is a predominance of parasympathetic ANS activity in sheep. Echocardiogram and the HRV reveal several modifications that happen during this period and allow an early and non-invasive identification of any disorders that may compromise the pregnancy.

Abstract: This study aimed at evaluating changes in the clinical and echocardiographic parameters of pregnant sheep, as well as the HRV indexes due to the physiological alterations that happen at this stage implicating in high maternal metabolic demands. For this purpose, the study evaluated 10 Dorper sheep through their pregnancy, starting from the second month until the day before birth, conducting clinical, echocardiographic and electrocardiographic examinations focused on the HRV. The echocardiogram was conducted in a doppler ultrasound device with a multifrequency sectorial transducer in bidimensional mode. The HRV indexes were obtained through the Televet $100 ®$ system. There were increases in the thickness of the interventricular septum during diastole starting from the third month, and in the internal diameter of the left ventricle during systole and diastole at the second and third months, while the ejection fraction increased as the pregnancy progressed. The size of the left atrium increased starting at the second month. The SDNN, RMSSD and PNN50 HRV indexes were higher at the fifth month of pregnancy and after delivery. There were no significant differences in the frequencydomain HRV indexes during pregnancy. The gestation leads to alterations in the clinical parameters and the activity of the autonomic nervous system. 
Keywords: sheep, gestation, hemodynamics, heart rate variability, cardiac output

\section{Introduction}

Pregnancy induces significant alterations in the maternal cardiovascular and hemodynamic systems, including increases in the cardiac output (CO), and reductions in arterial blood pressure (ABP) and vascular resistance, as well as a systemic vascular dilation [1]. The renin-angiotensin-aldosterone system (RAAS) is activated to increase the circulatory volume [2], since the volume of blood increases during pregnancy due to increases in the volume of plasma and, to a lesser degree, in the volume of red blood cells $[3]$.

The maternal and fetal cardiovascular functions may be evaluated based on both HR and HRV records, that is to say, short-term and long-term fluctuations in the HR [4]. HRV reflects the oscillatory influence of the sympathetic and parasympathetic branches of the ANS on the sinus node, and recording the HRV allow an analysis of ANS response to stress. Reductions in the HRV reveal sympathetic predominance, while increases in HRV reveal increases in the parasympathetic tone [5].

In humans, fetal HRV increases markedly after the $30^{\text {th }}$ week of pregnancy, reflecting the maturation of the cardiac activity control by the ANS. Reductions in the HRV are considered a sign of fetal impairment [6]. A constant worry for pregnant women is the development of pregnancy heart diseases, which may put the maternal health at risk. The echocardiographic evaluation allows an early diagnosis of these heart diseases and further studies in sheep using this method may contribute towards reducing the maternal morbidity and mortality rates.

The development of pregnancy heart diseases is a constant concern for pregnant women due to the possible risk they represent to the health of the mother. The echocardiographic evaluation allows an early diagnosis of these cardiopathies, and further 
research in sheep employing this method may help reduce the maternal morbidity and mortality rates. In addition, the relatively short pregnancy in the species and their low maintenance costs are favorable factors for such research to happen.

Production animals may generate highly valued individuals due to advancements in reproduction techniques, and neonatal mortality happens due to several factors, such as unfavorable environment, infectious and parasitic diseases, congenital anomalies and maternal frailty. In this scenario, the perinatal evaluation (for sheep, between the $60^{\text {th }}$ day after conception and the $28^{\text {th }}$ day after birth) in production animals may contribute significantly towards reducing losses during the pregnancy and the neonatal period [7].

Sheep have been widely employed in several experimental protocols in human medicine, as a model for remodeling in cases of heart failure [8], in fetal electrocardiography in obstetrics, and in pharmacological protocols in anesthesiology [9] due to the similarities with human cardiovascular anatomy and physiology, as well as availability, size, low maintenance costs and short pregnancy [10].

This study aims at analyzing the hemodynamic adaptations that happen during pregnancy in sheep through the echocardiographic and HRV parameters, as well as illustrating the importance of the perinatal evaluation in the species considering the high maternal metabolic demands during the pregnancy, possibly aiding in the identification of disorders that might compromise the pregnancy, reducing the risk of compromising the health of the mother and the viability of the fetus.

\section{Materials \& Methods}

\subsection{Study Location}

This study was conducted according to the animal well-being guidelines and approved by the Ethics Commission on Animal Use (CEUA, Comissão de Ética no Uso de Animais) of the School of Veterinary Medicine and Animal Science at Universidade Estadual 
Paulista "Júlio de Mesquita Filho", Botucatu Campus, under protocol CEUA0174/2016. The owners of the animals consented to the experimental plan and to the procedures performed. The study was conducted at the city of Botucatu, State of São Paulo, Brazil, at the Rubião Júnior District, latitude S-22.902107 and longitude W48.516534, from July 2017 to December 2017.

\subsection{Animais}

Ten Dorper Sheep (Ovis aries) were evaluated during pregnancy (152 days, or approximately 5 months) and the maternal parameters for weight, age, number of births and number of descendants were registered. The selected sheep, which presented a mean age of four years $(4.4 \pm 1.3$; the minimum age was two years and the maximum age seven years), underwent a clinical examination and animals presenting abnormalities were excluded from the study.

The sheep were kept in semi-confined and received animal feed twice a day and water ad libitum. In addition, they received a mineral mixture composed of $65 \%$ ground corn, $10 \%$ corn bran, $20 \%$ soy bran and $5 \%$ NC (nucleus) for sheep. The basic composition of the NC was: calcium (minimum) $120.0 \mathrm{~g} / \mathrm{kg}$; calcium (maximum) $220 \mathrm{~g} / \mathrm{kg}$; phosphorus (minimum) $18.0 \mathrm{~g} / \mathrm{kg}$; sodium (minimum) $78.0 \mathrm{~g} / \mathrm{kg}$; magnesium (minimum) 7,700.0 $\mathrm{mg} / \mathrm{kg}$; potassium (minimum) $10.0 \mathrm{~g} / \mathrm{kg}$; iron (minimum) $250.0 \mathrm{mg} / \mathrm{kg}$; zinc (minimum) 1,870.0 mg/kg; manganese (minimum) $650.0 \mathrm{mg} / \mathrm{kg}$; iodine (minimum) $30 \mathrm{mg} / \mathrm{kg}$; selenium (minimum) $8.00 \mathrm{mg} / \mathrm{kg}$; cobalt (minimum) $20.00 \mathrm{mg} / \mathrm{kg}$; monensin 600.00 $\mathrm{mg} / \mathrm{kg}$.

The clinical parameter compiled were: heart rate (beats per minute - bpm), respiratory rate (movements per minute $-\mathrm{mpm})$, rectal temperature $\left({ }^{\circ} \mathrm{C}\right)$, capillary refill time $(\mathrm{CRF})$, color of the mucosae, systolic arterial pressure (SAP), mean arterial pressure (MAP) and diastolic arterial pressure (DAP) through the PetMap® (Blood Pressure Measurement 
Device. Ramsey Medical, Inc. Patent No. D531, 313 S) oscillometric method, validated for the species as per Ulian et al. [11].

\subsection{Measurement of the systemic arterial pressure}

The measurement of the arterial blood pressure was performed on the left thoracic limb respecting the dotted lines indicated in the cuff, which was chosen according to the size of the animal ( $40 \%$ of the diameter of the limb) in order to ascertain the precision of the reading. This method detects the arterial pulse through oscillations and also registers the HR values. The maternal arterial blood pressure was also measured two and twenty-four hours after birth, and a mean was obtained from the three measurements.

\subsection{Echocardiogram}

The echocardiographic examination was performed using an ultrasound device (Mturbo Sonosite) with doppler function and a $2-8 \mathrm{MHz}$ multifrequency sectorial transducer. The following measurements were taken during diastole through the right parasternal window in a transversal section: thickness of the interventricular septum (IVSd); internal diameter of the left ventricle (LVIDd); and thickness of the left ventricle free wall (LVFWd). During systole, the following measurements were taken: thickness of the interventricular septum (IVSs), internal diameter of the left ventricle (LVIDs), and thickness of the left ventricle free wall (LVFWs). The means were calculated based on three measurements, all taken by the same operator (ASCA).

The diameter of the left atrium (LA) during systole, the diameter of the aorta (Ao) during diastole, the left atrium/aorta ratio (LA/Ao), the left ventricle shortening fraction (LVSF), the ejection fraction (EF), the pulmonary venous flow velocity (PVFV) and the pressure gradient between the right ventricle and the pulmonary artery (pulmonary pressure gradient) were also recorded. The following formula was used to calculate the LVSF: (LVIDd - LVIDs/LVIDd) x 100. 


\subsection{Measurement and Analysis of Maternal HRV}

The maternal electrocardiogram (ECG) was performed using a Televet 100 system (Kruuse®, version 4.1.3, Marslev, Denmark) as per the technique described by Nagel et al [12], which detects and registers the ECG via Bluetooth technology. This device employs an ECG filter that enables the visualization and analysis of the maternal and fetal cardiac activity, both at the same time and separately [13]. The filter extracts and amplifies the fetal ECG signal from the abdominal ECG signal of the mother. The maternal signal is recorded as a modified version of a conventional ECG register, while the fetal signal depends on the position of the fetus inside the uterus and, therefore, is not a standardized record due to the vector modifications, although the standard of electrocardiographic waves is maintained [14].

The electrodes used were adhesive hydrogel electrodes and were placed on the sheep as follows: the green electrode was placed three centimeters from the sternum, the yellow and black electrodes were placed respectively 20 and $30 \mathrm{~cm}$ below the withers at the left side of the thorax (Figure 1), and the red electrode was placed similarly to the yellow one at the right side of the thorax [15] (Figure 2). Data was recorded for eight minutes and transferred to a computer via Bluetooth technology.

The analysis of the HRV employed software Kubios (Biomedical Signal Analysis Group, Applied Physics Department of the University of Kuopio, Finland). Before being input in the software, the data was corrected manually in an Excel spreadsheet. The manual correction was performed due to artefacts that could possibly compromise the analysis, as described by Jonckheer-Sheehy et al. [16].

The minimum, mean and maximum values for HR and the HRV parameters were obtained from all records taken of an individual sheep. Based on the registered RR intervals, the HRV indexes SDNN (Standard Deviation of RR Intervals) and RMSSD 
(square root of the mean of successive differences between adjacent RR intervals) were calculated [17]. The time-domain index PNN50\% (proportion of differences between successive RR intervals exceeding 50 milliseconds) was also recorded.

In the frequency domain, spectral analysis was conducted through the Fast Fourier Transform (FFT) algorithm and the following indexes were compiled and expressed in normalized units (n.u.): the high frequency component (HF) varying between 0.15 and $0.4 \mathrm{~Hz}$; and the low frequency component (LF), varying between 0.04 and $0.15 \mathrm{~Hz}$.

\subsection{Statistical Analysis}

The results are shown as the mean, standard deviation, and minimum/maximum values. The test employed to verify the normality of the data was the KolmogorovSmirnov test, while the test employed to compare the proposed moments was Friedmann's test. The significance level adopted for the analysis was $p<0.05$. Friedmann's test was also used to verify if there were differences in the parameters during the pregnancy.

\section{Results}

The mean age of the sheep was four years $(4.4 \pm 1.3$; the minimum age was two years and the maximum age seven years), and the mean weight was $70 \mathrm{~kg}$. The mean number of births of the females used in the study was three births per animal, while the mean number of the descendants was four per female.

\subsection{Maternal clinical parameters}

Table 1 shows the maternal clinical parameters during pregnancy and 24 hours after birth. An increase in heart rate and respiratory rate was observed during the last month of pregnancy, and the difference was statistically significant when comparing with other periods in the pregnancy. 
There were also significant differences in the HR values obtained through the oscillometric method at distinct moments, with higher values occurring starting at the fourth month of pregnancy and peaking 24 hours after birth. The diastolic arterial blood pressure obtained through the same method also presented differences between the moments and peaked 24 hours after birth. On the other hand, the systolic blood pressure presented a marked increase during the second month of pregnancy, subsequently decreasing over the remainder of the pregnancy before increasing again 24 hours after birth.

\subsection{Maternal echocardiographic parameters}

Table 2 shows the maternal echocardiographic parameters obtained during pregnancy. There were statistically significant increases in the IVSs and IVSd values starting from the third month of pregnancy, and in the LVFWs values in the $2^{\text {nd }}$ and $5^{\text {th }}$ months. The LA presented a statistically significant increase in size from the $2^{\text {nd }}$ to the $4^{\text {th }}$ month of pregnancy before decreasing in the $5^{\text {th }}$ month in comparison with the previous values, and after birth in comparison with pregnancy as a whole. There was an increase in the LA/Ao ratio during the pregnancy, but there were no statistically significant differences between the moments analyzed.

LVIDd and LVIDs diverged significantly across the moments studied, increasing during the second and third months of pregnancy. On the other hand, LVFWd did not diverge significantly across the moments. The EF increased significantly, as the pregnancy progressed, before decreasing after birth. There were no statistically significant differences in the LVSF values. The differences between the echocardiographic parameters and the moments evaluated are represented in Table 2 as superscript letters. 
Figure 3 shows the maternal echocardiographic parameters that presented significant differences across the evaluated moments.

\subsection{Maternal HRV indexes}

Table 3 shows the maternal HRV indexes during pregnancy and after birth. According to the results, there was a statistically significant difference in the duration of the RR interval across the moments studied, which was longer during the $5^{\text {th }}$ month of pregnancy in comparison with the previous months, before decreasing after birth. The shortest durations were recorded on the $2^{\text {nd }}$ and $4^{\text {th }}$ months of pregnancy.

The mean HR obtained through the HRV analysis diverged significantly between the moments, with marked reductions on the $3^{\text {rd }}$ and $5^{\text {th }}$ months of pregnancy. The values increased again after birth, although without surpassing the ones recorded during the $2^{\text {nd }}$ and $4^{\text {th }}$ months of pregnancy. Minimum HR diverged significantly across the moments evaluated, with the highest values recorded on the $2^{\text {nd }}$ and $4^{\text {th }}$ months of pregnancy before decreasing during the $5^{\text {th }}$ month and increasing slightly after birth. Maximum HR also diverged significantly, decreasing markedly on the $5^{\text {th }}$ month of pregnancy and after birth.

The time-domain HRV index SDNN also presented statistically significant differences between the moments, increasing on the $5^{\text {th }}$ month of pregnancy and after birth. Similar phenomena were observed for the RMSSD and PNN50 indexes, both of which represent parasympathetic activity. The normalized (n.u.) LF and HF indexes and the LF/HF ratio did not diverge significantly across the moments studied.

The analysis of each specific moment during pregnancy revealed statistically significant differences for minimum and maximum HR on the $3^{\text {rd }}$ and $5^{\text {th }}$ months of pregnancy; mean HR and RR interval on the $2^{\text {nd }}$ month and after birth; SDNN between the $2^{\text {nd }}$ and $4^{\text {th }}$ months; RMSSD between the $2^{\text {nd }}$ and $3^{\text {rd }}$ months, and between the $2^{\text {nd }}$ and $4^{\text {th }}$ months; and PNN50 between the $3^{\text {rd }}$ and $5^{\text {th }}$ months. 


\section{Discussion}

\subsection{Clinical parameters}

In this study, the HR values obtained from the maternal clinical examination and through the oscillometric method were both high during the last month of pregnancy. According to Prestes \& Landim-Alvarenga [18], the concentrations of progesterone remain high in sheep until the last week of pregnancy, with the placenta producing five times more progesterone than the ovaries towards the end of the gestation. In the final third part of the pregnancy, estrogen causes a dilation in the cotyledonary vessels, effectively doubling the amount of blood that reaches the placenta. Therefore, high HR values in sheep may be explained by the high levels of progesterone, which promotes vasodilation [19], and by the increased blood flow to the placenta. Fetal growth is also accelerated during the last months of pregnancy, which leads to more compressed abdominal organs and, therefore, higher sympathetic activity.

In addition, the results obtained in this study for HR are similar to those obtained by Nagel et al. [20], who observed that the maternal HR increased continuously during the last three months of pregnancy in equines. These increases in HR may also be explained by the increased venous return during pregnancy, as mentioned by Almeida et al. [21]. Despite the clinical increase in HR, the mean for maternal HR remained within the reference values for the species $(90-115 \mathrm{bpm})$.

There was an increase in the values of MAP and SAP in the last month of pregnancy in comparison with the previous month. The increased blood volume during pregnancy is also caused by the activation of the RAAS. The action of progesterone promotes natriuresis [22] and reduction of the peripheral vascular resistance [23] during pregnancy, while aldosterone and estrogen promote sodium retention [24]. 
We believe that the high HR and ABP values observed during the last few months of pregnancy are caused by an increase in the energetic metabolism of the mother due to the increase size of the fetus, the activation of the RAAS and the high concentrations of thyroid hormones during this period. According to Araújo et al. [25], pregnant sheep presented increase concentrations of thyroid hormones and this increase is related to the energy metabolism. In non-pregnant animals, these hormones are considered indicators of the metabolic and nutritional state of the herd. In pregnant sheep, the increased activity of the thyroid in comparison with other animals happens due to the increases in the concentrations of ligating proteins, in the secretion of thyrotrophic factors by the placenta, and in the response of the hypophysis to the thyroid-stimulating hormone (TSH) related to the secretion of the thyrotropin-releasing hormone (TRH) by the hypothalamus.

The elevated pressure values observed in this study may be caused by the levels of estrogen and the activation of the RAAS. Further studies are needed to verify whether the alterations in $\mathrm{ABP}$ in sheep are equivalent to those observed in women with preeclampsia. Pre-eclampsia is a syndrome that affects $3 \%$ to $5 \%$ women and is diagnosed when the pregnant woman presents high blood pressure caused by the pregnancy during the last months of pregnancy. The syndrome is characterized by excessive retention of sodium and water in the kidneys of the mother [26]. In these cases, there are often injuries in the vascular endothelium, leading to arterial spasms mainly in the kidneys, brain and liver. The causes of pre-eclampsia are still not fully understood. Some women are genetically predisposed to developing the affliction and associations have been identified between pre-eclampsia and genetic variants involved in inflammation, oxidative stress and the RAAS [27].

It is important to note that the method used to measure the arterial blood pressure and the stress caused by handling may have contributed to the high blood pressure values 
observed in the species. The animals proved to resist being handled and the blood pressure was conducted with the sheep in station, which also reflects the difficulties faced when working in the field. Even though the oscillometric method has been validated for the species, it overestimates the pressure values. According to Pettit \& Brown [28], the measurement of the arterial blood pressure is fraught with errors. Mercury sphygmomanometry remains the gold standard, but the method has been replaced by a plethora of devices, including aneroid and automatic machines. However, these devices present inherent limitations, with aneroid manometers presenting a deterioration in precision over time and requiring recalibration each 6 to 12 months.

The maternal blood pressure values and the HR obtained through the oscillometer after birth were both high in this study. Close to the time of birth, the cardiac output increases due to the increase venous return from each uterine contraction, increasing further after birth due to the decompression of the abdominal organs [29]. In addition, there is an increase in the systolic volume immediately after birth, possibly due to the release in the occlusion of the vena cava, with the $\mathrm{CO}$ and the HR returning to the normal values two weeks after birth in women [30].

Metcalfe \& Parer [31], in a study with pregnant sheep that aimed to evaluate the hemodynamic alterations and compare them to the human species, noted that pregnancy in sheep leads to increases in $\mathrm{CO}, \mathrm{HR}$ and blood volume, and reductions in peripheral vascular resistance, which is similar to the alterations observed in women towards the end of pregnancy. The authors observed a HR of $108 \mathrm{bpm}$ in the last month of pregnancy, which is similar to the values observed in this study, which presented a mean HR of 106 bpm on the last month of pregnancy. They also observed that the SAP did not diverge between the studied moments during pregnancy (although the animals were evaluated under the effects of general anesthesia), but presented an increase 24 hours after birth. 
This is in line with the results of this study, which observed peak blood pressure values 24 hours after birth.

We observed that the respiratory rate was higher during the last month of pregnancy than in the previous months. According to Soma-Pillay et al. [32], there is a significant increase in the demand for oxygen and a 40-50\% increase in minute ventilation during a normal pregnancy. This happens due to a $15 \%$ increase in the metabolic rate and a $20 \%$ increase in oxygen consumption. However, according to Guyton \& Hall [33], it is believed that the high levels of progesterone during pregnancy help increase the minute ventilation even further, considering that progesterone increases the sensitivity of the respiratory core to carbon dioxide, which promotes an increase in minute ventilation. Simultaneously, the growing uterus compresses the contents of the abdomen and applies pressure against the diaphragm, reducing the total distension of the diaphragm and leading to an increase in the respiratory rate to maintain the extra ventilation.

\subsection{Echocardiographic parameters}

The echocardiographic evaluation of the structure and function of the heart during pregnancy requires understanding the normal physiological alterations that happen during this period, particularly the increased blood volume (preload), the reduced systemic vascular resistance (afterload), and the increased cardiac output. In addition, the cardiac output increases by $30 \%$ to $60 \%$ during the first and second trimesters of pregnancy, first as a result of the increased preload and systolic volume, and later as a result of the increased HR. There are divergences in the literature regarding whether the cardiac output increases even further during the third trimester, and these divergences may be explained by the individual variation of the mothers [34].

In this study, we observed increases in the thickness of the interventricular septum in diastole and in systole in comparison with the start of pregnancy. In women, the mass of 
the left ventricle increases $5 \%$ to $10 \%$ during pregnancy before returning to normal levels six months after birth. Ventricular hypertrophy happens proportionally to the increase of the workload imposed on the heart by pregnancy [35].

The maternal echocardiographic parameter LVIDd presented increases in this study, particularly during the second and third months of pregnancy. Due to the hemodynamic modifications that happen during pregnancy, the venous return increases during this period due to the increased blood volume, particularly during the first trimester of pregnancy. This increase in the blood volume and in the cardiac output during pregnancy results in a physiological state of volume overload, which leads to a dilation of the heart and reversible eccentric hypertrophy [36]. Serial measurements of the final diastolic dimensions of the left atrium and left ventricle in M-Mode highlights these alterations [31]. Despite the increased volume, the pressures within the pulmonary vessels and the central venous pressures do not increase during pregnancy, possibly due to the dilation and reduction of vascular resistance in the systemic and pulmonary vascular beds [32].

The systolic and diastolic diameters of the LV were higher in this study than in the study conducted by Acorda \& Pajas [37] in both pregnant and non-pregnant sheep. The authors observed LVIDd values of $2.16 \mathrm{~cm}$ in pregnant sheep and $2.18 \mathrm{~cm}$ in nonpregnant sheep, and LVIDs values of $1.19 \mathrm{~cm}$ in pregnant sheep and $1.24 \mathrm{~cm}$ in nonpregnant sheep. These differences highlight the need for further studies standardizing echocardiographic parameters in sheep according to breed and body weight, since the sheep used in this study presented an average weight of $70 \mathrm{~kg}$, while the ones in Acorda \& Pajas [37] study presented an average weight of $20 \mathrm{~kg}$. The authors also observed differences in the echocardiographic parameters according to age and lactation, and the internal diameter of the right ventricle also increased during pregnancy, which was not observed in this study. 
In this study, the EF increased as pregnancy progressed before decreasing 24 hours after birth. Studies regarding these indexes in M Mode have shown that the EF and the mean circumferential shortening rate of the fibers increase during pregnancy as a response to the increased systolic volume during this period. This increase happens during first and second trimesters in women before decreasing during the third trimester (Hall et al., 2011) [38].

The diameter of the LA increased during the third and fourth months of pregnancy, before decreasing during the last month of pregnancy and increasing again after birth. In a study conducted by Rublin et al. [39] with pregnant women, the diameter of the LA increased as the pregnancy progressed. The same happened in sheep, but there was a decrease in the fifth month. The increased values observed after birth may be explained by the increased venous return after decompression of the abdominal organs.

According to the maternal parameters observed in this study, the HR increased during pregnancy and septum hypertrophy was observed. LVIDs and LVIDd also increased, particularly at the beginning of pregnancy, but these results may have been influenced by the pregnancy hormones, since according to Fthenakis et al. [40], the blood flow of the sheep during the estrous cycle increases by $10 \mathrm{~mL} / \mathrm{minute}$ due to the high concentrations of estrogen and progesterone. In case of fertilization, this flow decreases before starting to increase gradually starting at the $20^{\text {th }}$ day of pregnancy, which may have contributed to the increased LVIDs and LVIDd values observed in this study during the second and third months of pregnancy.

Locatelli et al. (2011) [41] conducted a study to assess if the echocardiographic parameters in sheep are similar to those in humans, concluding that the echocardiographic parameters for the systolic and diastolic functions of the LV in young adult sheep may be 
extrapolated for human adults, supporting the use of sheep models of human cardiac disease in translational research.

\subsection{Maternal HRV}

Regarding the maternal HRV indexes and the behavior of the HR, the highest records for minimum, mean and maximum HR happened during the fourth month pregnancy and after birth, and they came accompanied by inversely proportional variations in the RR intervals. Carpenter et al. [42] observes that changes happen in the HRV during pregnancy and they seem to reflect a substantial reduction in the parasympathetic tone and an increase in sympathetic activity until the end of the first trimester of pregnancy in women. In contrast with the findings of Carpenter et al [42], Alam et al. [43], in a study aiming to evaluate the behavior of HRV in pregnant women, observed more parasympathetic dominance during the first trimester of pregnancy and a gradual reduction in vagal activity during the second and third trimesters, while sympathetic activity was lower during the first trimester before increasing gradually during the second and third trimesters, together with an increase in HR. We believe, according to our results, that, during the evaluation of the HR in production animals in the field, environmental factors that might result in increased HR, such as the stress caused by handling, should also be considered.

The increased blood flow may have contributed to increase the distention of the arterial walls and, therefore, promote the activation of the baroreflex, the inhibition of the bulbar vasoconstrictor center, and the stimulation of the vagal parasympathetic center [33].

We observed increases in the maternal HRV indexes RMSSD and PNN50 as pregnancy progressed, revealing an increase in parasympathetic activity. The same happened for the index SDNN, which illustrates activity of both ANS branches. Therefore, as pregnancy progresses there seems to be a predominance of parasympathetic activity, which may represent an attempt by the ANS to maintain the balance of the 
reactions that happen during this period, considering that the uterus increases in size as the pregnancy advances, increasing the compression of the vena cava and abdominal aorta, decreasing the venous return and increasing sympathetic activation [44]. The parasympathetic predominance may be caused by this increase in the size of the uterus as the pregnancy advances, which promotes an increase of the intrathoracic pressure and leads to increased vagal stimulus. In addition, the distention of the forestomach in sheep due to feeding and the size of the uterus may have exacerbated the parasympathetic stimulus.

We believe that a series of events during pregnancy, such as the size of the uterus, hormonal action, and the baroreflex, all contribute towards that the changes that happen in the ANS activity during this period, but these mechanisms are complex and still not fully understood, warranting further research in the field. Stone et al [45] observed a significant association between the position of the mother with the fetal heart rate (FHR), with the HRV indexes SDNN and RMSSD decreasing in the semi-inclined and supine positions, ,revealing that towards the end of a healthy pregnancy, the position of the mother affects the FHR and the HRV. The authors believe that these effects are caused by the fetus adapting to positions that could lead to a mild hypoxic stress. Stacey et al [46] observed that the mother sleeping in supine position increases the chances of the fetus dying.

Individual factors should also be considered during the HRV analysis in production animals and when data is collected on the field. The HRV analysis is a method that may be employed to evaluate the ANS in sheep, but when interpreting the indexes recorded in this study, one should consider that they reflect the HRV of animals under conditions of stress. In addition to the influence of pregnancy, there is also an influence of how the animals are being handled, which means that when obtaining HRV data to use as 
reference, it is necessary to consider under which conditions these references are obtained, considering factors such stress in the field, nutrition and afflictions.

Trenk et al. [47] assessed HR and HRV in bovines during pregnancy and observed that the HRV indexes SDNN and RMSSD did not present any significant alterations during the last 14 weeks of pregnancy, but SDNN was higher in cows than in heifers, suggesting a higher sympathovagal tone in the cows and that age has a degree of influence on the autonomic activity. Quevedo et al. [14], in a study assessing maternal and fetal HRV in Holstein cows, observed a significant decrease in the maternal index SDNN during the last month of pregnancy. The index RMSSD also decreased during the period, but without statistical significance. The age of the animals used in this study may have contributed towards the results observed for the HRV indexes, which is in line with Trenk et al [47], who observed differences in the index SDNN between cows and heifers.

There were no statistically significant differences for the frequency-domain HRV indexes, but that may be explained by the relatively small sample size in this study. The HF indexes corresponds to respiratory modulation and is an indicator of the action of the vagus nerve over the heart. The LF indexes is a result of the joint action of the sympathetic and parasympathetic components over the heart, with sympathetic predominance $[48,49$, 50].

Since the HF component of HRV is centered around the RR, breathing is a factor that should be considered when analyzing the HRV because the RR varies between individuals and change according to physiological conditions, such as exercise $[17,51]$. Therefore, the RR in sheep is a factor that should be considered when interpreting the HF index, since the animals in this study presented increased respiratory rates. In addition, the blood flow to the respiratory system increases during pregnancy [19, 52], and evaporation through breathing is an important heat loss in sheep exposed to high 
temperatures [31], which is something that may have interfered with the results observed in this study for RR and the HF index.

Chaswal et al [4], in a study aiming to assess the behavior of HRV in pregnant women, observed sympathetic hyperactivity and sympathovagal imbalance in patients with preeclampsia in comparison with controls comprised of women with normal blood pressure and non-pregnant women. The decrease in parasympathetic activity was obvious due to the significantly lower values for the RMSSD and HF (n.u.) indexes in the group with pre-eclampsia. The increase in the LF (n.u.) index reveals increased sympathetic activity, while the higher $\mathrm{LF} / \mathrm{HF}$ ratio indicates a sympathovagal imbalance, attributed to the sympathetic dominance and reduction of the vagal tone in women with pre-eclampsia. This shows that the HRV is an index capable of revealing afflictions that could develop as the pregnancy advances and potentially compromise the health of both mother and fetus.

In this study and in previous studies from the literature, we highlighted the alterations in the cardiovascular parameters in sheep during pregnancy and emphasized the need to monitor the mothers during this period due to the series of hemodynamic alterations that happen. In addition, extensive studies are conducted on the cardiovascular parameters and HRV of sheep since the species has a heart that is similar to the human heart in several aspects, including the dimensions of the chambers, the coronary anatomy, and the magnitude of the hemodynamic parameters such as blood pressure, heart rate and cardiac output. In addition, the autonomic innervations of the heart are similar in sheep and humans $[53,54,55]$.

The creation of a physiological extra-uterine environment that can support the continuous growth of the fetus and the development of organs with no connection to the biological placenta has the potential to improve the survival rates and reduce morbidity 
in premature births [56]. There are echocardiographic parameters that characterize the clinical state of the fetal cardiovascular system. Doppler ultrasound is used to assess the cerebrovascular, placental and fetal blood flow, as well as the vascular resistance through the calculation of pulsatility indexes for the umbilical artery and the middle cerebral artery, respectively [57]. A study conducted by Ozawa et al. [58] aiming to employ an extra-uterine environment (artificial placenta) for neonatal development revealed that is resembled the natural state in the placenta and promoted a stable and sustainable hemodynamic state for a period of three weeks.

Under this light, we want to emphasize the importance of describing the echocardiographic parameters in pregnant sheep and the hemodynamic behavior of the changes that happen during this period considering that studies regarding the development of artificial placentas have gained relevance recently.

It's important for translational research monitoring the sheep during pregnancy through a cardiovascular evaluation ensures a healthy pregnancy, avoiding any possible risks to the health of both mother and fetus, which could lead to economic losses, particularly when using fixed time artificial insemination (FTAI), and the loss of descendants that could potentially contribute towards the profitability of the sector.

This study has some inherent limitations. The high values for the arterial blood pressure may have been caused because the measurements were taken with the animals in station as we were not allowed to position the animals in decubitus due to their cost. The manual restraint of the sheep increased their stress since the animals were not used to handling, which may have influenced the results for ABP and the HRV indexes. The small sample size may have contributed towards non-significant results, and the choice of breed may have influenced the echocardiographic parameters since the Dorper breed is considered a meat-producing sheep. 


\section{Conclusions}

The echocardiographic evaluation highlighted the hemodynamic alterations that happen in sheep during pregnancy. During this period in sheep, there is a predominance of parasympathetic activity and it is believed that this is an attempt to maintain the sympathovagal balance in the face of the adaptations that happen in the organism of the mother to accommodate the fetus. This is illustrated by the HRV, which has proven to be a feasible technique in production animals that may contribute towards reducing economic losses in the sector, since a healthy pregnancy may generate high performance descendants and, therefore, high zootechnical value, having a positive impact in the agribusiness sector.

Author Contributions: Conceptualization, M.L.G.L and S.B.C.; methodology, D.O.L.F. and M.C.G.; formal analysis, A.S.C.A. and M.C.F.L.; investigation, R.A.P. and L.G.A.; resources, A.L.H.A. and R.T.T.; writing — original draft preparation, A.S.C.A.; writingreview and editing, A.S.C.A.; visualization, M.H.T.; supervision, M.H.T. and S.B.C.; project administration, M.L.G.L.; funding acquisition, M.L.G.L. All authors have read and agreed to the published version of the manuscript.

\section{Conflicting Interests}

The authors declare they have no conflicting interests.

\section{Acknowledgements}

The authors want to thank CAPES (Coordenação de Aperfeiçoamento de Pessoal de Nivel Superior) for the scholarship provided, FAPESP (Fundação de Amparo à pesquisa do Estado de São Paulo) for the research grant, the Large Animal Medical Clinic at FMVZ-UNESP, Botucatu, Brazil, and the sheep farm Estrela do Vale, Sítio Vale Verde, Botucatu-SP, Brazil. 


\section{Funding}

This study was supported by FAPESP (Fundação de Amparo à Pesquisa do Estado de

São Paulo), grant number 2017/15121-9.

\section{References}

1. Orabona, R.; Prefumo, F.; Zanardini, C.; Magri, R.; Loardi, C.; Cappa, V.; Calza, S.; Frusca, T.; Acharya, G. Maternal functional hemodynamics in uncomplicated twin pregnancies: a longitudinal study using impedance cardiography. Acta Obstet. Gynecol. Scand. 2018, 00, 1-22.

2. Ferrazi, E.; Stampaliija, T.; Monasta, L.; Martino, D.; Vonck, S.; Gyselaers, W. Maternal hemodynamics: a method to classify hypertensive disorders of pregnancy. Am. J. Obstet. Gynecol. 2018, 218, 1-11.

3. Haas, S.; Ghossein-doha, C.; Van Kuijk, S.M.J.; Van Drongelen, J.; Spaanderman, M. E. A. Physiological adaptation of maternal plasma volume during pregnancy: a systematic review and meta-analysis. Ultrasound Obstet. Gynecol. 2017, 49, 177187.

4. Chaswal, M.; Kapoor, R.; Batra, A.; Verma, S.; Yadav, S. Heart Rate Variability and Cardiovascular Reflex Tests for Assessment of Autonomic Functions in Preeclampsia. Int. J. Hypertens. 2018, 1-7.

5. Giese, H.; Dilly, M.; Gundelach, Y.; Hoffmann, G.; Schmicke, M. Influence of transrectal palpation training on cortisol levels and heart rate variability in cows. Theriogenology. 2018, 119, 238-244.

6. Nagel, C.; Aurich, J.; Aurich, C. Determination of heart rate and heart rate variability in the equine fetus by fetomaternal electrocardiography. Theriogenology. 2010, 73 973-983. 
7. Fragkou, I.A.; Mavrogianni, V.S.; Fthenakis, G.C. Diagnostic investigation of cases of deaths of newborn lambs. Small Ruminant Res. 2010, 92, 41-44.

8. Navarro, F.B.; Costa, F.D.A.; Mulinari, L.A.; Pimentel, G.K.; Roderjan, J.G.; Vieira, E.D.; Noronha, L.E.; Miyague, N.I. Avaliação do comportamento biológico de homoenxertos valvares pulmonares descelularizados: estudo experimental em ovinos. Rev. Bras. Cir. Cardiovasc. 2010, 25, 377-387.

9. Hallowell, G.D.; Potter, T.J.; Bowen, I.M. Reliability of quantitative echocardiography in adult sheep and goats. BMC Vet. Res. 2012, 8, 1-11.

10. Grazul-Bilska, A.T.; Borowicz, P.P.; Johnson, M.L.; Minten, M.A.; Bilski, J.J.; Wroblewski, R.; Redmer, D.A.; Reynolds, L.P. Placental development during early pregnancy in sheep: vascular growth and expression of angiogenic factors in maternal placenta. Reproduction. 2010, 140, 165-174.

11. Ulian, C.M.V.; Carvajal, A.P.L.; Velasquez, D.R.B.; Neto, F.J.T.; Lourenço, M.L.G.; Chiacchio, S.B., Acurácia dos métodos oscilométrico (petmap®) e doppler para aferição indireta da pressão arterial em cordeiros. Cienc. Anim. Bras. 2016, 17, 593600.

12. Nagel, C.; Aurich, J.; Palm, F.; Aurich, C. Heart rate and heart rate variability in pregnant warmblood and Shetland mares as well as their fetuses. Anim. Reprod. Scie. 127, 2011, 183-187.

13. Nagel, C.; Erber, R.; Bergmaier, C.; Wulf, M.; Aurich, J.; Möstl, E.; Aurich, C. Cortisol and progestin release, heart rate and heart rate variability in the pregnant and postpartum mare, fetus and newborn foal. Theriogenology. 2012, 78, 759-767.

14. Quevedo, D.A.C.; Lourenço, M.L.G.; Bolaños, C.D.; Alfonso, A.; Ulian, C.M.V.; Chiacchio, S.B. Maternal, fetal and neonatal heart rate and heart rate variability in Holstein cattle. Pesq. Vet. Bras. 2019, 39, 286-291. 
15. Ille, N.; Erber, R.; Aurich, C.; Aurich, J. Comparison of heart rate and heart rate variability obtained by heart rate monitors and simultaneously recorded electrocardiogram signals in nonexercising horses. J. Vet. Behav. 2014, 9, 341-346.

16. Jonckheer-Sheehy, V.S.M.; Vinke, C.M.; Ortolani, A. Validation of a Polar® human heart rate monitor for measuring heart rate and heart rate variability in adult dogs under stationary conditions. J. Vet. Behav. 2012, 7, 205-212.

17. Tarvainen, M.P.; Niskanen, J.P.; Lipponen, J.A.; Ranta-aho, P.O.; Karjalainen, P.A.; Kubios HRV - Heart rate variability analysis software. Comput. Methods Programs Biomed. 2014, 113, 210-220.

18. Prestes, N.C.; Landim-Alvarenga, F.C. Obstetrícia Veterinária. Rio de Janeiro: Guanabara Koogan, 2006, p.70-73.

19. Constantine, M.M. Physiologic and pharmacokinetic changes in pregnancy. Front Pharmacol. 2014, 5, 1-5.

20. Nagel, C.; Aurich, J.; Trenk, L.; Ille, N.; Drillich, M.; Pohl, W.; Aurich, C. Stress response and cardiac activity of term and preterm calves in the perinatal period. Theriogenology. 2016a, 86, 1498-1505.

21. Almeida, V.T.; Uscategui, R.A.R.; Silva, P.D.A.; Avante, M. L.; Simões, A.P.R.; Vicenti, W.R.R. Hemodynamic gestacional adaptation in bitches. Cienc. Rural. 2017, 47, 1-6.

22. Ganaie, B.A.; Khan, M.Z.; Islam, R.; Makhdoomi, D.M.; Qureshi, S.; Wani, G.M. Evaluation of different techniques for pregnancy diagnosis in sheep. Small Rumin. Res., 2009, 85, 135-141.

23. Juengel, J. L.; Hudson. N.L.; Whiting, L.; McNatty, K.P. Effects of Immunization against Bone Morphogenetic Protein 15 and Growth Differentiation Factor 9 on 
Ovulation Rate, Fertilization, and Pregnancy in Ewes. Biol. Reprod. 2004, 70, 557561.

24. May, L.E.; Glaros, A.; Yeh, H.W.; Clapp III, J.F.; Gustafson, K.M. Aerobic exercise during pregnancy influences fetal cardiac autonomic control of heart rate and heart rate variability. Early Hum. Dev. 2010, 86, 213-217.

25. Araújo, C.A.C.; Nikolaus, J.P.; Morgado, A.A.; Monteiro, B.M.; Rodrigues, F.A.M.L.; Vechiato, T.A.F.; Soares, P.C.; Sucupira, M.C.A. Perfil energético e hormonal de ovelhas Santa Inês do terço médio da gestação ao pós-parto. Pesq. Vet. Bras. 2014, 34,1251-1257.

26. Mol, B.W.J.; Roberts, C.T.; Thangaratinam, S.; Magee, L.A.; de Groot, C.J.M.; Hofmeyr, G.J. Pre-eclampsia. Lancet. 2016, 387, 999-1011.

27. Rana, S.; Karumanchi, S.A.; Lindheimer, M.D. Angiogenic factors in diagnosis, management, and research in preeclampsia. Hypertension. 2014, 63, 198-202.

28. Pettit, F.; Brown, M.A. The management of pre-eclampsia: what we think we know. Eur. J. Obstet. Gynecol. Reprod. Biol. 160, 6-12.

29. Schrick, F.N.; Surface, R.A.; Pritchard, J.Y.; Dailey, R.A.; Townsend. E.C.; Inskeep, E.K. Ovarian Structures during the Estrous Cycle and Early Pregnancy in Ewes. Biol. Reprod. 1993, 49, 1133-1140.

30. Hunter, S.; Robson, S.C.; Adaptation the maternal heart in pregnancy. Br. Heart J. 1992, 68, 540-543.

31. Metcalfe, J.; Parer, J.T. Cardiovascular changes during pregnancy in ewes. Am. J. Physiol. 1966, 210, 821-825.

32. Soma-Pillay, P.S.; Piercy, C.N.; Tolppanen, H.E.L.I.; Mebazaa, A. Physiological changes in pregnancy. Cardiovasc. J. Afr. 2016, 27, 89-94. 
33. Guyton, A.C.; Hall, J.E. Tratado de Fisiologia médica. 13 ed. Rio de Janeiro: Elsevier, p.2019-220; p.1063, 2017.

34. Nagel, C.; Trenk, C.; Aurich, J.; Wulf, M.; Aurich, C. Changes in blood pressure, heart rate and blood profile in mares during the last 3 months of gestation and the peripartum period. Theriogenology. 2016b, 86, 1-9.

35. Simmons, L.A.; Gillin, A.G.; Jeremy, R.W. Structural and functional changes in left ventricle during normotensive and preeclamptic pregnancy. Am. J. Physiol. Heart Circ. Physiol. 2002, 283, H1627-H1633.

36. Eghbali, M.; Deva, R.; Alioua, A.; Minosyan, T.Y.; Ruan, H.; Wang, Y.; Toro, L.; Stefani, E. Molecular and functional signature of heart hypertrophy during pregnancy. Circ. Res. 2005, 96, 1208-1216.

37. Acorda, J.A.; Pajas, A.M.G.A. M-mode Echocardiographic Values in Male and Female Philippine Sheep (Ovis aries) (Artiodactyla: Bovidae) by Age and Status of Lactation and Pregnancy. Philipp. J. Vet. Med. 2015, 52, 11-20.

38. Yadegari, M. Normal echocardiographic findings in Lori-Bakhtiari sheep. Vet. Med. Sci. 2014, 6, 45-48.

39. Rublin, S.; Damani, P.M.; Pinto, E.R. Cardiac size and performance during pregnancy estimated with echocardiography. Am. J. Cardiol. 1977, 40, 534-540.

40. Fthenakis, G.C.; Arsenos, G.; Brozos, C.; Fragkou, I.A.; Giadinis, N.D.; Giannenas, I.; Mavrogianni, V.S.; Papadopoulos, E.; Valasi, I. Health management of ewes during pregnancy. Anim. Reprod. Sci. 2012, 130, 198-212.

41. Locatelli, P.; Olea, F.D.; Lorenzi, A.; Salmo, F.; Janavel, G.L.V.; Hnatiuk, A.P.; Guevara, E.; Crottogini, A.J., Reference values for echocardiographic parameters and indexes of left ventricular function in healthy, young adult sheep used in 
translational research: comparison with standardized values in humans. Int. J. Clin. Exp. Med. 2011, 4, 258-264.

42. Carpenter, R.E.; da Silva, L.A.; Emery, S.J.; Uzun, O.; Rassi, D.; Lexwis, M.J. Changes in heart rate variability and QT variability during the first trimester of pregnancy. Physiol. Meas. 2015, 36, 531-545.

43. Alan, T.; Choudhary, A.K.; Kumaran, S. Maternal heart rate variability during different trimesters of pregnancy. Natl. J. Physiol. Pharm. 2018, 8, 1475-1480.

44. Humphries, A.; Mirjalili, S.A.; Tarr, G.P.; Thompson, J.M.D. The effect of supine positioning on maternal hemodynamics during late pregnancy. J. Matern. Fetal Neonatal Med. 2018, 1-8.

45. Stone, P.R.; Burgess, W.; Mcintyre, J.P.R.; Gunn, A.J.; Lear, C.A.; Bennet, L.; Mitchell, E.A.; Thompson, J.M.D.. Effect of maternal position on fetal behavioural state and heart rate variability in healthy late gestation pregnancy. J. Physiol. 2017, $595,1213-1221$.

46. Stacey, T.; Thompson, J.; Mitchell, E.A.; Ekeroma, A.J.; Zuccollo, J.M., Mccowan, L.M.E. Association between maternal sleep position and risk of late stillbirth: a case control study. BMJ. 2011, 342, d3403.

47. Trenk, L.; Kuhl, J.; Aurich, J.; Aurich, C.; Nagel, C. Heart rate and heart rate variability in pregnant dairy cows and their fetuses determined by fetomaternal electrocardiography. Theriogenology. 2015, 84, 1405-1410.

48. Borrell, E.V.; Langbein, J.; Després, G.; Hansen, S.; Leterrier, C.; Forde, J.M.; Forde, R. M.; Minero, M.; Mohr, E.; Prunier, A.; Valance, D.; Veissier, I. Heart rate variability as a measure of autonomic regulation of cardiac activity for assessing stress and welfare in farm animals- A review. Physiol. Behav. 2007, 92, 293-316. 
49. Brown, T.E.; Beightol, L.A.; Koh, J.; Eckberg, D.L. Important influence of respiration on human R-R interval power spectra is largely ignored. J. Appl. Physiol. 1993, 75, 2310-2317.

50. Evrengül, H.; Tanriverdi, H.; Dursunoglu, D.; Kaftan, A.; Kuru, O.; Unlu, U.; Kilic, M.; Time and frequency domain analyses of heart rate variability in patients with epilepsy. J. Epilepsy. Res. 2005, 63, 131-139.

51. Laitio, T.; Jalonen, J.; Kuusela, T.; Scheinin, H. The role of heartrate variability in risk stratification for adverse postoperativecardiac events. Anesth. Analg. 2007, 105, $1548-1560$.

52. Jensen, D.; Webb, K.A.; Davies, G.A.L.; O’Donnell, D.E. Mechanical ventilatory constraints during incremental cycle exercise in human pregnancy: implications for respiratory sensation. J. Physiol. 2008, 19, 4735-4750.

53. Levy, M.N. Autonomic interactions in cardiac control. Ann. N Y Acad. Sci. 1990, 601, 209-21.

54. Booth, L.C.; Bennet, L.; Barrett, C.J.; Guild, S.J.; Wassink, G.; Gunn, A.J.; Malpas, S.C.; Cardiac-related rhythms in sympathetic nerve activity in preterm fetal sheep. Am. J. Physiol. Regul. Integr. Comp. Physiol. 2007, 293, 185-190.

55. Thayer, J.F.; Åhs, F.; Fredrikson, M.; Sollers III, J.J.; Wager, D.T. A meta-analysis of heart rate variability and neuroimaging studies: implications for heart rate variability as a marker of stress and health. Neurosci. Biobehav. Rev. 2012, 36, 747756.

56. Partridge, E.A.; Davey, M.G.; Hornick, M.A.; Mcgovern, P.E.; Mejaddam, A. Y.; Vrecenak, J.D.; Mesas-burgos, C.; Olive, A., Caskey; R.C., Weiland; T.R., Han; J., Schupper; A.J., Connelly, J.T.; Dysart, K.C.; Rychik, J.; Hedrick, H.L.; Peranteau, 
W.H.; Flake, A.W. An extra-uterine system to physiologically support the extreme premature lamb. Nat Commun. 2017, 8, 1-15.

57. Acharya, G.; Erkinaro, T.; Makikallio, K.; Lappalainen, T.; Rasanen, J. Relationships among Doppler-derived umbilical artery absolute velocities, cardiac function, and placental volume blood flow and resistance in fetal sheep. Am. J. Physiol. Heart Circ. Physiol. 2004, 286, H1266-1272.

58. Ozawa, K.; Davey, M.G.; Tian, Z.; Hornick, M.A.; Mejaddam, A.Y.; McGovern, P.E.; Flake, A.W.; Rychik, J. Fetal echocardiographic assessment of the cardiovascular impact of prolonged support in the EXTrauterine Environment for Neonatal Development (EXTEND) system. Ultrasound. Obstet. Gynecol. 2019. doi: 10.1002/uog.20295. 
Table 1 - Maternal clinical parameters (mean, standard deviation, minimum, maximum) obtained during the pregnancy and after the birth of the lambs.

\begin{tabular}{|c|c|c|c|c|c|c|}
\hline $\begin{array}{l}\text { Clinical } \\
\text { Parameters }\end{array}$ & $\begin{array}{l}2 \text { months of } \\
\text { pregnancy }\end{array}$ & $\begin{array}{l}3 \text { months of } \\
\text { pregnancy }\end{array}$ & $\begin{array}{l}4 \text { months of } \\
\text { pregnancy }\end{array}$ & $\begin{array}{l}5 \text { months of } \\
\text { pregnancy }\end{array}$ & Hours after birth & $\mathbf{P}$ \\
\hline HR (bpm) & $\begin{array}{c}80 \pm 12.75^{\mathrm{abc}} \\
(64 ; 112)\end{array}$ & $\begin{array}{c}90 \pm 23.05^{\mathrm{ab}} \\
(44 ; 140)\end{array}$ & $\begin{array}{l}84 \pm 20.48^{\mathrm{abc}} \\
(58 ; 124)\end{array}$ & $\begin{array}{c}106 \pm 27.47^{\mathrm{c}} \\
(48 ; 152)\end{array}$ & - & $* 0.007$ \\
\hline RR (mpm) & $\begin{array}{c}47 \pm 19.82^{\mathrm{a}} \\
(28 ; 112)\end{array}$ & $\begin{array}{c}50 \pm 22.56^{\mathrm{a}} \\
(24 ; 100)\end{array}$ & $\begin{array}{c}42 \pm 12.72^{\mathrm{a}} \\
(20 ; 60)\end{array}$ & $\begin{array}{c}83 \pm 34.23^{\mathrm{b}} \\
(44 ; 140)\end{array}$ & - & $* 0.000$ \\
\hline $\mathrm{T}\left({ }^{\circ} \mathrm{C}\right)$ & $\begin{array}{l}38.8 \pm 0.25^{\mathrm{ac}} \\
(38.5 ; 39.3)\end{array}$ & $\begin{array}{l}38.5 \pm 0.42^{\mathrm{b}} \\
(38.3 ; 38.8)\end{array}$ & $\begin{array}{c}38.9 \pm 0.45^{\mathrm{abc}} \\
(38.3 ; 39.8)\end{array}$ & $\begin{array}{c}39.3 \pm 0.26^{\text {abc }} \\
(39.1 ; 39.9)\end{array}$ & - & $* 0.000$ \\
\hline Mucosae & 1 & 1 & 1 & 1 & - & \\
\hline CRT & 2 & 2 & 2 & 2 & - & \\
\hline $\begin{array}{l}\mathrm{ABP}(\mathrm{mmHg}) \\
\text { Diastolic }\end{array}$ & $\begin{array}{c}112 \pm 43.20^{\mathrm{abc}} \\
(60 ; 225)\end{array}$ & $\begin{array}{c}108 \pm 31.87^{\mathrm{ab}} \\
(60 ; 170)\end{array}$ & $\begin{array}{c}120 \pm 37.06^{\mathrm{abc}} \\
(60 ; 185)\end{array}$ & $\begin{array}{c}119 \pm 27.30^{\mathrm{abc}} \\
(65 ; 170)\end{array}$ & $\begin{array}{c}2: 127 \pm 27.14(75 ; 165)^{\mathrm{c}} \\
24: 146 \pm 35.34(100 ; 225)^{\mathrm{abc}}\end{array}$ & 0.001 \\
\hline Mean & $\begin{array}{c}143 \pm 35.64^{\mathrm{a}} \\
(95 ; 230)\end{array}$ & $\begin{array}{c}130 \pm 28.80^{\mathrm{cd}} \\
(80 ; 190)\end{array}$ & $\begin{array}{c}138 \pm 34.99^{\mathrm{abd}} \\
(75 ; 205)\end{array}$ & $\begin{array}{c}142 \pm 24.75^{\text {abcd }} \\
(85 ; 180)\end{array}$ & $\begin{array}{c}2: 144 \pm 27.72(85 ; 175)^{\text {abcd }} \\
24: 154 \pm 31.79(90 ; 230)^{\mathrm{d}}\end{array}$ & $* 0.004$ \\
\hline Systolic & $\begin{array}{c}195 \pm 38.26^{\mathrm{ab}} \\
(130 ; 270)\end{array}$ & $\begin{array}{c}173 \pm 31.66^{\mathrm{abc}} \\
(130 ; 230)\end{array}$ & $165 \pm 44.20^{\mathrm{c}}(90 ; 250)$ & $\begin{array}{c}171 \pm 25.89^{\mathrm{abc}} \\
(125 ; 220)\end{array}$ & $\begin{array}{l}2: 165 \pm 32.43(100 ; 205)^{\mathrm{abc}} \\
24: 184 \pm 35.28(105 ; 240)^{\mathrm{a}}\end{array}$ & $* 0.003$ \\
\hline HR Pet Map & $\begin{array}{l}98 \pm 23.64^{\mathrm{a}} \\
(70 ; 155)\end{array}$ & $\begin{array}{c}88 \pm 24.04^{\mathrm{a}} \\
(40 ; 135)\end{array}$ & $\begin{array}{c}114 \pm 27.64^{\mathrm{b}} \\
(60 ; 170)\end{array}$ & $\begin{array}{c}126 \pm 24.22^{c} \\
(75 ; 170)\end{array}$ & $\begin{array}{l}2: 128 \pm 24.78(75 ; 175)^{\mathrm{d}} \\
24: 131 \pm 28.45(80 ; 205)^{\mathrm{e}}\end{array}$ & $* 0.000$ \\
\hline
\end{tabular}

Mucosae: $1=$ normal color, $2=$ pale, $3=$ congested; CRT: $1=>2$ seconds, $2=<2$ seconds. Normality test: Kolmogorov-Smirnov; Comparison between moments: Friedmann's test. *significance: $\mathrm{p}<0.05$; ${ }^{\text {ab }}$ different superscripted letters in the same line indicate significant differences between the periods evaluated. 
Table 2 - Maternal echocardiographic parameters (mean, standard deviation, minumum, maximum) in Dorper sheep obtained during pregnancy and 24 hours after birth.

\begin{tabular}{|c|c|c|c|c|c|c|}
\hline $\begin{array}{l}\text { Echocardiographic } \\
\text { Parameters }\end{array}$ & 2 months of pregnancy & $\begin{array}{l}3 \text { months of } \\
\text { pregnancy }\end{array}$ & $\begin{array}{l}4 \text { months of } \\
\text { pregnancy }\end{array}$ & $\begin{array}{l}5 \text { months of } \\
\text { pregnancy }\end{array}$ & 24 hours after birth & $\mathbf{p}$ \\
\hline IVSd (cm) & $0.91 \pm 0.21(0.57 ; 1.51)^{\mathrm{a}}$ & $1.04 \pm 0.17(0.76 ; 1.39)^{\mathrm{abc}}$ & $1.0 \pm 0.17(0.78 ; 1.39)^{\mathrm{bc}}$ & $1.01 \pm 0.17(0.69 ; 1.33)^{\mathrm{bc}}$ & $1.08 \pm 0.24(0.76 ; 1.63)^{\mathrm{bc}}$ & $* 0.045$ \\
\hline LVIDd (cm) & $4.86 \pm 0.52(3.90 ; 5.89)^{\mathrm{a}}$ & $4.53 \pm 0.67(3.54 ; 6.05)^{\mathrm{b}}$ & $4.24 \pm 0.55(3.02 ; 5.06)^{\mathrm{abc}}$ & $4.28 \pm 0.69(2.65 ; 5.55)^{\mathrm{abc}}$ & $4.26 \pm 0.68(3.11 ; 5.20)^{\mathrm{ac}}$ & $* 0.009$ \\
\hline LVFWd (cm) & $1.10 \pm 0.31(0.76 ; 2.02)$ & $1.04 \pm 0.24(0.61 ; 1.58)$ & $1.05 \pm 0.15(0.63 ; 1.26)$ & $1.21 \pm 0.26(0.88 ; 1.89)$ & $1.14 \pm 0.21(0.79 ; 1.51)$ & 0.178 \\
\hline IVSs (cm) & $1.46 \pm 0.21(1.17 ; 1.95)^{\mathrm{a}}$ & $1.53 \pm 0.24(1.19 ; 2.08)^{\mathrm{ab}}$ & $1.51 \pm 0.18(1.29 ; 1.83)^{\mathrm{a}}$ & $1.55 \pm 0.24(1.20 ; 2.21)^{\mathrm{ac}}$ & $1.57 \pm 0.19(1.20 ; 1.88)^{\mathrm{ad}}$ & 0.048 \\
\hline LVIDs (cm) & $3.15 \pm 0.42(2.39 ; 3.91)^{\mathrm{a}}$ & $2.89 \pm 0.5(1.86 ; 3.97)^{\mathrm{b}}$ & $2.65 \pm 0.47(1.95 ; 3.59)^{\mathrm{bc}}$ & $2.56 \pm 0.49(1.58 ; 3.41)^{\mathrm{c}}$ & $2.64 \pm 0.55(1.67 ; 3.34)^{\mathrm{b}}$ & $* 0.004$ \\
\hline LVFWs cm & $1.76 \pm 0.27(1.23 ; 2.15)^{\mathrm{ab}}$ & $1.54 \pm 0.29(1.05 ; 2.39)^{\mathrm{a}}$ & $1.46 \pm 0.23(0.88 ; 1.75)^{\mathrm{ab}}$ & $1.62 \pm 0.20(1.32 ; 2)^{\mathrm{b}}$ & $1.56 \pm 0.27(1.20 ; 2.08)^{\mathrm{ab}}$ & $* 0.006$ \\
\hline EF $(\%)$ & $64 \pm 5.7(55 ; 76)^{\mathrm{a}}$ & $66 \pm 6.6(53 ; 81)^{\mathrm{b}}$ & $68 \pm 8.5(53 ; 83)^{\mathrm{bc}}$ & $70 \pm 7.33(59 ; 83)^{\mathrm{ac}}$ & $68 \pm 6.6(61 ; 82)^{\mathrm{bc}}$ & $* 0.04$ \\
\hline LFSF (\%) & $35 \pm 4.33(29 ; 45)$ & $36 \pm 5.18(27 ; 49)$ & $38 \pm 6.85(28 ; 51)$ & $40 \pm 6.07(31 ; 52)$ & $38 \pm 5.4(33 ; 50)$ & 0.062 \\
\hline LA (cm) & $4.08 \pm 0.42(3.56 ; 4 ; 96)^{\mathrm{a}}$ & $4.15 \pm 0.25(3.58 ; 4.50)^{\mathrm{bc}}$ & $4.20 \pm 0.36(3.33 ; 4.84)^{\mathrm{bc}}$ & $3.83 \pm 0.46(3.04 ; 4.73)^{\mathrm{abc}}$ & $3.90 \pm 0.43(3.32 ; 4.89)^{\mathrm{abc}}$ & $* 0.008$ \\
\hline Ao $(\mathbf{c m})$ & $2.36 \pm 0.34(1.87 ; 2.96)$ & $2.25 \pm 0.29(1.76 ; 2.78)$ & $2.31 \pm 0.37(1.44 ; 2.98)$ & $2.26 \pm 0.28(1.84 ; 2.94)$ & $2.33 \pm 0.31(1.84 ; 2.92)$ & 0.415 \\
\hline LA/Ao & $1.74 \pm 0.19(1.45 ; 2.19)$ & $1.86 \pm 0.21(1.51 ; 2.24)$ & $1.85 \pm 0.28(1.42 ; 2.51)$ & $1.73 \pm 0.24(1.38 ; 2.40)$ & $1.67 \pm 0.14(1.50 ; 2.04)$ & 0.065 \\
\hline $\begin{array}{l}\text { Pulmonary } \\
\text { Velocity }(\mathbf{c m} / \mathbf{s})\end{array}$ & $79.99 \pm 11.40(65.70 ; 106.20)$ & $79.28 \pm 11.64(61 ; 111.30)$ & $79.41 \pm 12.51(64.60 ; 105)$ & $79.93 \pm 11.05(61 ; 103.60)$ & $79.69 \pm 11.7(61 ; 104.10)$ & 0.973 \\
\hline $\begin{array}{l}\text { Pressure Gradient } \\
(\mathrm{mmHg})\end{array}$ & $2.64 \pm 0.77(1.73 ; 4.51)$ & $2.58 \pm 0.78(1.49 ; 4.96)$ & $2.62 \pm 0.85(1.67 ; 4.41)$ & $2.64 \pm 0.75(1.49 ; 4.31)$ & $2.66 \pm 0.73(149 ; 4.33)$ & 0.942 \\
\hline
\end{tabular}

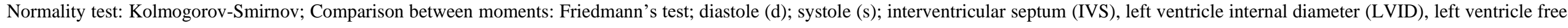

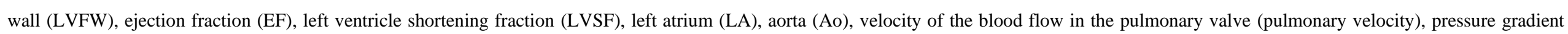

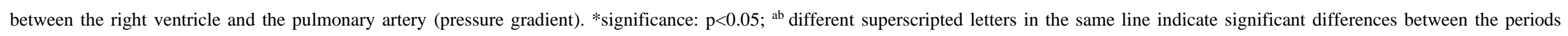
evaluated. 
Table 3 - Maternal HRV indices (mean, standard deviation, minimum and maximum) during the gestational period and 24 hours after parturition in Dorper ewes.

\begin{tabular}{|c|c|c|c|c|c|c|}
\hline $\begin{array}{l}\text { Maternal } \\
\text { HRV }\end{array}$ & $\begin{array}{l}2 \text { months of } \\
\text { pregnancy }\end{array}$ & $\begin{array}{l}3 \text { months of } \\
\text { pregnancy }\end{array}$ & $\begin{array}{l}4 \text { months of } \\
\text { pregnancy }\end{array}$ & $\begin{array}{l}5 \text { months of } \\
\text { pregnancy }\end{array}$ & $\begin{array}{l}24 \text { hours after } \\
\text { birth }\end{array}$ & $\mathbf{p}$ \\
\hline Min HR & $\begin{array}{l}86 \pm 23^{\mathrm{ab}} \\
(43 ; 122)\end{array}$ & $\begin{array}{c}41 \pm 3.37^{\mathrm{a}} \\
(39 ; 52)\end{array}$ & $\begin{array}{c}75 \pm 9.27^{\mathrm{ab}} \\
(63 ; 99)\end{array}$ & $\begin{array}{c}44 \pm 4.45^{\mathrm{b}} \\
(39 ; 53)\end{array}$ & $\begin{array}{c}46 \pm 5.22^{\mathrm{ab}} \\
(42 ; 61)\end{array}$ & $* 0.000$ \\
\hline Mean HR & $\begin{array}{c}114 \pm 23.27^{\mathrm{a}} \\
(66 ; 148)\end{array}$ & $\begin{array}{c}81 \pm 9.48^{\mathrm{ab}} \\
(65 ; 103)\end{array}$ & $\begin{array}{c}114 \pm 12.1^{\mathrm{ab}} \\
(93 ; 134)\end{array}$ & $\begin{array}{l}81 \pm 15^{\mathrm{ab}} \\
(65 ; 132)\end{array}$ & $\begin{array}{c}94 \pm 15^{\mathrm{b}} \\
(72 ; 117)\end{array}$ & $* 0.000$ \\
\hline Max HR & $\begin{array}{c}158 \pm 21.78^{\mathrm{ab}} \\
(96 ; 186)\end{array}$ & $\begin{array}{c}141 \pm 17.2^{\mathrm{a}} \\
(99 ; 150)\end{array}$ & $\begin{array}{c}183 \pm 8.58^{\mathrm{ab}} \\
(165 ; 197)\end{array}$ & $\begin{array}{c}136 \pm 12.48^{\mathrm{b}} \\
(101 ; 149)\end{array}$ & $\begin{array}{c}138 \pm 16.44^{\mathrm{ab}} \\
(98 ; 150)\end{array}$ & $* 0.000$ \\
\hline $\mathrm{RR}$ (ms) & $\begin{array}{c}554 \pm 136.68^{\mathrm{a}} \\
(406 ; 914)\end{array}$ & $\begin{array}{c}749 \pm 90.67^{\mathrm{ab}} \\
(580 ; 925)\end{array}$ & $\begin{array}{c}529 \pm 57.2^{\mathrm{ab}} \\
(446 ; 643)\end{array}$ & $\begin{array}{c}757 \pm 113.46^{\mathrm{ab}} \\
(455 ; 926)\end{array}$ & $\begin{array}{l}653 \pm 107^{\mathrm{b}} \\
(515 ; 835)\end{array}$ & $* 0.000$ \\
\hline SDNN (ms) & $\begin{array}{c}9.95 \pm 4.60^{\mathrm{a}} \\
(4.70 ; 18.40)\end{array}$ & $\begin{array}{l}12.51 \pm 7.45^{a b} \\
(6.70 ; 32.60)\end{array}$ & $\begin{array}{c}17.20 \pm 14.84^{b} \\
(4.20 ; 55.10)\end{array}$ & $\begin{array}{c}36.83 \pm 24.32^{\mathrm{ab}} \\
(9.60 ; 96.70)\end{array}$ & $\begin{array}{c}45.01 \pm 22.37^{\mathrm{ab}} \\
(11.50 ; 93.20)\end{array}$ & $* 0.000$ \\
\hline RMSSD (ms) & $\begin{array}{c}6.42 \pm 3.59^{\mathrm{a}} \\
(2.80 ; 15.20)\end{array}$ & $\begin{array}{c}10.49 \pm 5.40^{\mathrm{b}} \\
(5.70 ; 24.40)\end{array}$ & $\begin{array}{l}11.58 \pm 9.84^{\mathrm{bc}} \\
(2.70 ; 33.60)\end{array}$ & $\begin{array}{c}29.23 \pm 23.55^{\mathrm{abc}} \\
(7.60 ; 91.60)\end{array}$ & $\begin{array}{l}36.74 \pm 28.47^{a b c} \\
(12.30 ; 127.40)\end{array}$ & $* 0.000$ \\
\hline PNN50 \% & $\begin{array}{c}0.29 \pm 0.77^{a b} \\
(0 ; 2.41)\end{array}$ & $\begin{array}{c}1.04 \pm 1.5^{\mathrm{a}} \\
(0 ; 5.36)\end{array}$ & $\begin{array}{c}2.46 \pm 5.27^{\mathrm{ab}} \\
(0 ; 18.75)\end{array}$ & $\begin{array}{c}7.84 \pm 13.4^{\mathrm{b}} \\
(0 ; 50)\end{array}$ & $\begin{array}{l}6.24 \pm 4.83^{\mathrm{ab}} \\
(0.80 ; 16.57)\end{array}$ & $* 0.000$ \\
\hline LF (n.u.) & $\begin{array}{c}75.91 \pm 14.98 \\
(46.18 ; 94.79)\end{array}$ & $\begin{array}{c}75.25 \pm 8.56 \\
(58.03 ; 86.80)\end{array}$ & $\begin{array}{c}73.69 \pm 9.19 \\
(60.33 ; 91.98)\end{array}$ & $\begin{array}{c}74.58 \pm 17.89 \\
(25.34 ; 95.46)\end{array}$ & $\begin{array}{c}76.07 \pm 14.21 \\
(48.16 ; 93.71)\end{array}$ & 0.653 \\
\hline HF (n.u.) & $\begin{array}{l}24.05 \pm 14.98 \\
(5.14 ; 53.81)\end{array}$ & $\begin{array}{c}24.96 \pm 9.15 \\
(13.17 ; 45.85)\end{array}$ & $\begin{array}{c}25.33 \pm 8.90 \\
(7.98 ; 39.56)\end{array}$ & $\begin{array}{l}25.28 \pm 17.86 \\
(4.53 ; 74.61)\end{array}$ & $\begin{array}{l}23.88 \pm 14.18 \\
(6.25 ; 51.83)\end{array}$ & 0.653 \\
\hline $\mathrm{LF} / \mathrm{HF}$ & $\begin{array}{c}5.58 \pm 5.22 \\
(0.86 ; 18.43)\end{array}$ & $\begin{array}{c}3.51 \pm 1.59 \\
(1.18 ; 6.59)\end{array}$ & $\begin{array}{c}3.58 \pm 2.63 \\
(1.53 ; 11.53)\end{array}$ & $\begin{array}{c}5.17 \pm 5.03 \\
(0.34 ; 21.07)\end{array}$ & $\begin{array}{c}5.70 \pm 4.14 \\
(1.39 ; 14.99)\end{array}$ & 0.421 \\
\hline
\end{tabular}

Normality test: Kolmogorov-Smirnov; *significance: $\mathrm{p}<0.05$; comparison between moments: Friedmann's test; n.u. = normalized units. HR: heart rate; Min: minimum; Max: proportion of differences between successive RR intervals exceeding 50 milliseconds; HF: high frequency; LF: low frequency; ab different superscripted letters in the same line indicate significant differences between the periods evaluated. 


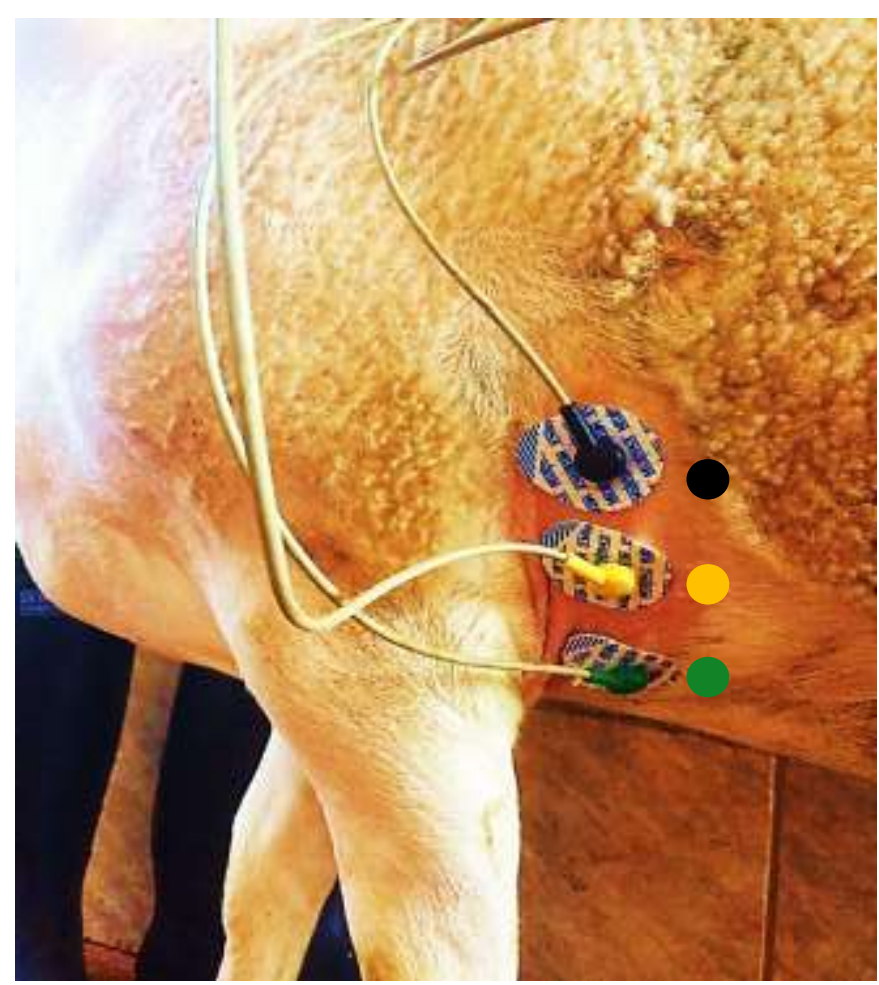

Figure 1. Position of the electrodes (left side of the thorax) for acquisition of HRV data in Dorper sheep.

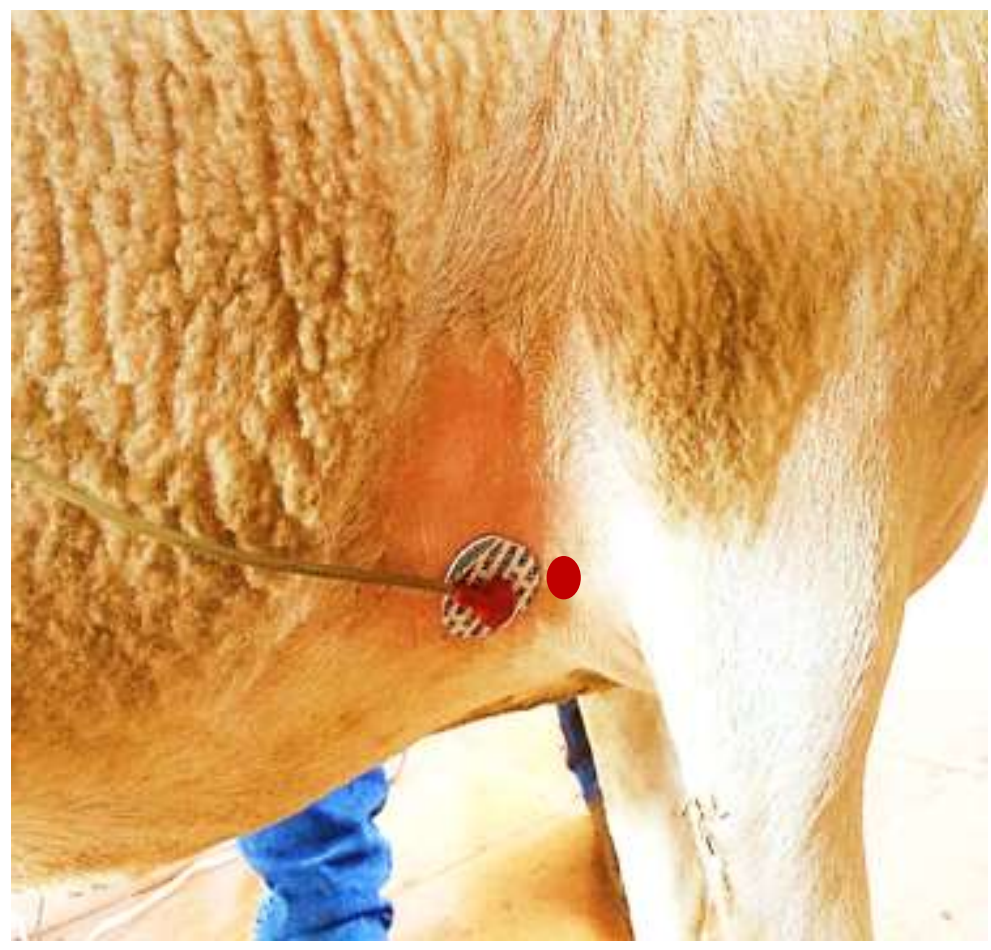

Figure 2. Position of the electrodes (right side of the thorax) for acquisition of HRV data in Dorper sheep. 


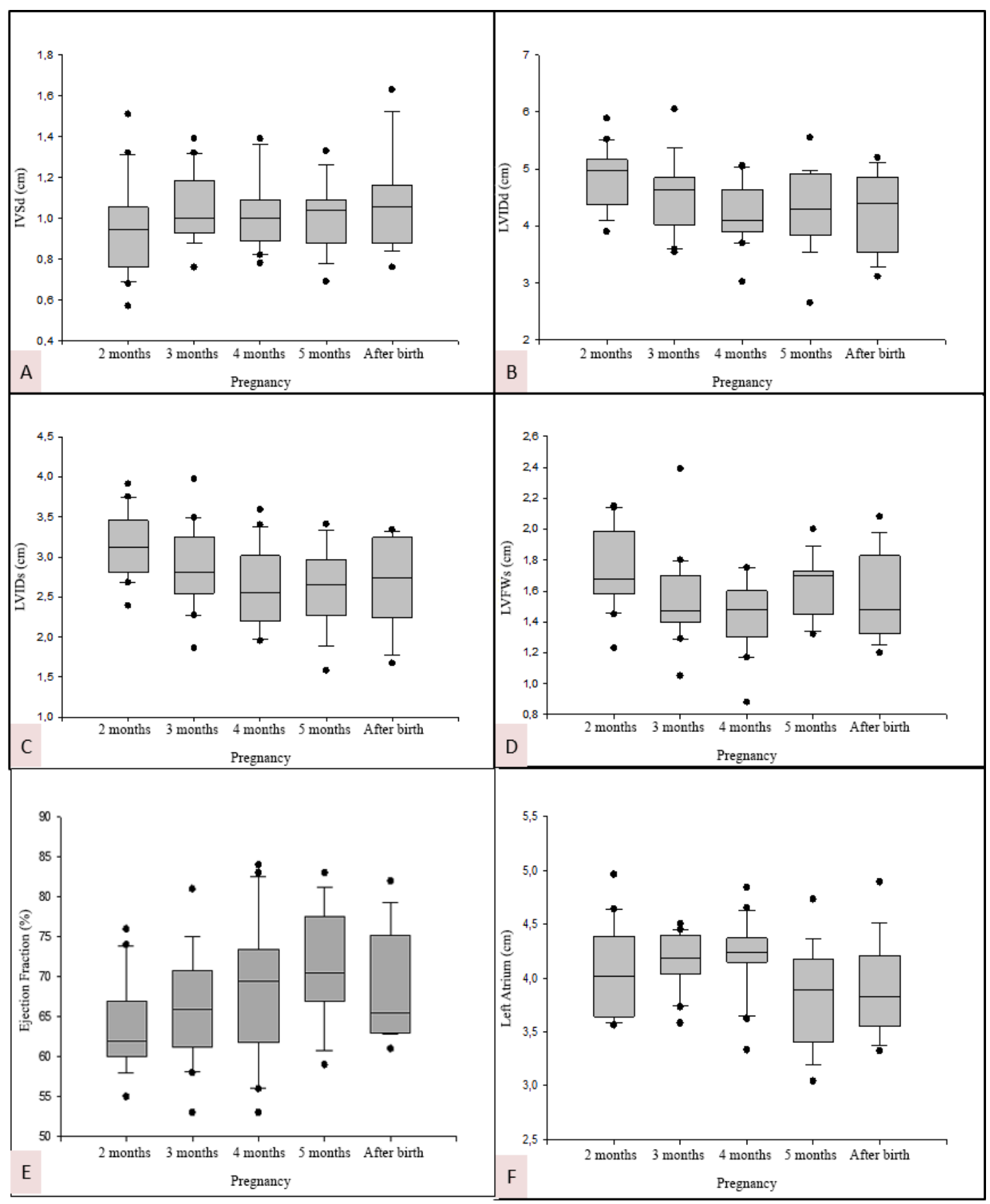

Figure 3. Maternal echocardiographic parameters in Dorper sheep that presented significant differences in the periods evaluated: A- IVS(d), B- LVID(d), C- LVID(s), D- LVFW(s), E- Ejection fraction, F- Size of the left atrium. 